\title{
ПРИМЕНЕНИЕ ТЕОРИИ АВАТАРОВ В БАНКОВСКОМ МАРКЕТИНГЕ ВИП-СЕГМЕНТА
}

\author{
(C) 2020 Ершова Алёна Викторовна \\ аспирант кафедры маркетинга \\ Санкт-Петербургский государственный экономический университет, Россия, Санкт-Петербург \\ E-mail: alena.tsyura@mail.ru \\ (c) 2020 Шубаева Вероника Георгиевна \\ доктор экономических наук, профессор, \\ профессор кафедры маркетинга, проректор по учебной и методической работе \\ Санкт-Петербургский государственный экономический университет, Россия, Санкт-Петербург \\ E-mail: choubaeva@yandex.ru
}

Макроэкономическая ситуация, в которой оказался банковский сектор России к 2020 г., неизбежно привела к необходимости цифровой трансформации в части внутренних процессов и каналов взаимодействия с клиентами, в том числе во внедрении аналитики так называемых «больших данных» (Big Data). При этом если говорить о взаимодействии с банковскими клиентами ВИП-сегмента, необходимо разрабатывать такие банковские инструменты, которые будут отличаться от аналогов массового рынка. Банкам необходима комплексная, динамическая модель управления информацией о потребителе банковского сектора ВИП-сегмента, которая будет основана на системе показателей, определяющих аватар потребителя банковских услуг. Исследование представителей того или иного аватара целевого клиента не может производиться посредством классических инструментов маркетинговых исследований. Для решения данной проблемы авторами разработана методика содержательного анализа контента социальных сетей, являющихся ресурсами массовой консолидации представителей указанного аватара. Проведенный анализ позволил охарактеризовать лексический и тональный характер сообщений, которые будут наиболее благосклонно восприняты представителями аватара банковского сектора ВИП-сегмента, что поможет сформировать эффективную контент-стратегию взаимодействия с представителями данного аватара.

Ключевые слова: банковский маркетинг, ВИП-сегмент, анализ контента, анализ социальных сетей, больщие данные

В настоящее время банки занимают основное место в системе финансового посредничества, и за последние два десятилетия макроэкономическая значимость банковского сектора существенно повысилась. В начале 2000-х годов отношение банковских активов к ВВП составляло лишь $32,6 \%$, в то время как по состоянию на 2019 год этот показатель увеличился втрое и достиг значения 90,6\%.

В 2020 году в банковском секторе России, несмотря на пандемию коронавируса и вызванный ею глобальный экономический кризис, наблюдаются основные мировые тенденции: цифровая трансформация в части внутренних процессов и каналов взаимодействия с клиентами; использование технологии искусственного интеллекта, которая позволяет собирать глубокую пошаговую информацию о клиентах; усовершенствование системы предоставления пер- сонализированных услуг; внедрение аналитики так называемых «больших данных» (Big Data), в том числе с использованием технологий машинного обучения [6].

Аналитики KPMG ожидают, что банковский сектор полностью изменится к 2030 году. По их мнению, рынок будет более конкурентным, чем сейчас. Это произойдет благодаря развитию технологий, которое вызовет изменение в работе персонала. Основным конкурентным преимуществом станет использование цифровых технологий для адаптации банковских продуктов под индивидуальные нужды каждого клиента [1].

Большое влияние на банковский сектор оказывают финансовые технологии и инновации, в корне изменившие операционные процессы банков, предлагаемыми ими услуги и используемые маркетинговые механизмы взаимодействия с клиентами. В первую очередь, рас- 
тет доля электронных платежей. По прогнозам аналитиков ЦБ, к 2030 году платежи через интернет-сети будут составлять $100 \%$ от общего объема электронных платежей, что будет актуально не только для массового сегмента, но и для ВИП - клиентов.

Для более эффективного взаимодействия с банковскими клиентами данного сектора, необходимо разработать такие банковские инструменты, которые будут отличаться от аналогов массового рынка [2].

Влияние всех вышеперечисленных тенденций указывает на то, что банкам необходима комплексная, динамическая модель управления информацией о потребителе банковского сектора ВИП-сегмента, которая будет автоматизированной, то есть работать на основе функционирования CRM-системы. Модель должна быть основана на системе показателей, определяющих аватар потребителя банковских услуг ВИПсегмента.

Аватар клиента (или идеальный портрет клиента, персонаж клиента) - это глубокое, пошаговое описание конкретного представителя целевой аудитории. Методика «составление аватара целевого клиента» является более подвинутым вариантом сегментации как процесса анализа целевой аудитории, которая получила свое развитие благодаря появлению методик аналитики больших объемов данных (Big Data) [4].

Базовый вариант описания аватара клиента, как правило, включает следующую информацию [5]:

- гео-демографические показатели: место проживания, возраст, пол, образование, уровень дохода, семейное положение, род занятий, вероисповедание, размер семьи;

- психографические показатели: образ жизни, наличие свободного времени, хобби;

- поведенческие показатели: статус потребления, лояльность, отношение к продуктам и услугам (например, банка);

Составление аватара ВИП-клиента помогает ответить на следующие вопросы:

- С какой проблемой («болью») клиент приходит в банк? Как он сам формулирует мотив обращения?

- По каким критериям клиент принимает решение о том, в какой банк обратиться?

- Какой информацией клиент уже обладает о товарах (услугах) банка? Какие у него имеются возражения?
- Из каких источников клиент получает вызывающую у него доверие информацию о банковских продуктах и услугах?

Как правило, у банка существует несколько аватаров ВИП-клиентов. По крайней мере, на каждый из видов услуг должен быть свой портер идеального клиента. Из практики следует, что аватары должны быть не только у «идеальных» клиентов, но и у «негативных клиентов», что поможет не допускать потерь эффективности.

При этом стоит отметить, что исследование представителей того или иного аватара целевого клиента не может производиться посредством классических инструментов маркетинговых исследований. В первую очередь это обусловлено тем, что период эволюции аватара может составлять от 5 лет, что не позволяет с достаточной долей уверенности определить конкретных представителей данного аватара, которые в будущем сформируют платежеспособный спрос в исследуемом сегменте банковских услуг. Более того, исследование уже полностью сформированных представителей данного аватара может в недостаточной степени коррелировать с новыми его представителями через 5 лет в части основных потребительских свойств. Эффективным решением в данном случае будет исследование значительных массивов людей, достаточная доля которых будет формировать описанный платежеспособный спрос. Следовательно, первичной задачей в данном случае является определение ресурсов массовой консолидации представителей аватара. В качестве базиса могут выступать социальные сети, так как в них возможно осуществлять поиск значительной доли населения мира и страны. В рамках самих социальных сетей люди консолидируются в сообщества по интересам, что позволяет предположить, что значительная часть представителей рассматриваемого аватара консолидируются в единообразных сообществах. Поскольку объектом текущего исследования авторов является аватар, относящийся к банковскому ВИП-сегменту, то одними из определяющих интересов его представителей на первичных этапах их развития являются способы и направления развития бизнеса, бизнесновости, способы развития бизнеса в цифровой среде и hr-навыки. Следовательно, для целей повышения эффективности исследования необходимо сформировать исследовательскую выборку на основе наиболее посещаемых сообществ в социальных сетях, сформированных вокруг обо- 
значенных категорий интересов.

В качестве исследуемой социальной сети был выбрана сеть «Вконтакте». Данный выбор обусловлен наличием в данной социальной сети открытого API, что значительно повышает возможности автоматизации исследовательского процесса. В соответствии с описанными ранее потенциальными интересами аватара, были отобраны следующие социальные сообщества:

1. «Forbes» - https://vk.com/forbes. Данное сообщество является официальной страницей русской редакции Forbes, и пишет об историях успеха и поражений предпринимателей, новых идеях для бизнеса и инвестиций, а также публикует авторитетные рейтинги. Аудитория сообщества составляет более 900 тысяч человек.

2. «Стартапы и бизнес» - https://vk.com/ vcru. Данное сообщество консолидирует информацию относительно специфики ведения бизнеса в России и мире, бизнес-технологиях, моделях роста, стартапах и крупном бизнесе и развитии рынков. Аудитория сообщества составляет более 840 тысяч человек.

3. «Spark»- https://vk.com/gospark. Данное сообщество посвящено в первую очередь успешным решениям в маркетинге. Аудитория сообщества составляет более 48 тысяч человек.

4. «HR» - https://vk.com/humanrelations. Данное сообщество посвящено эффективным решениям в области ректрутинга. Аудитория сообщества составляет более 51 тысячи человек.

Процесс описания аватара состоит из двух базовых этапов:

1. Анализ контента, представленного в приведенных социальных сообществах. Целью данного анализа является детальное описание области интересов представителей аватара, особенностей взаимодействия представителей аватара, а также лексической и ментальной специфики аватара.

2. Анализ профилей участников приведенных сообществ. Данный анализ позволяет сформировать демографические и психографические особенности представителей аватара.

В рамках данной статьи рассматривается исключительно анализ контента. Данный анализ проводится посредствам языка программирования python и программы jupyter notebook. Объектом анализа в данном случае выступают записи в профилях сообществ. Идея данного анализа базируется на том, что ядро интересов представителей аватара, а также специфика восприя- тия и изложения информации формируется под воздействием контента в представленных социальных сообществах. Следовательно, маркетинговые решения в сегменте ВИП - банкинга, сформированные в корреляции с данным контентом, будут более эффективны с точки зрения привлечения представителей аватара. В данном случае анализ контента может быть реализован посредством 3 инструментов [3]:

1. Содержательный анализ контента. Данный вид анализа направлен на идентификацию лексических категорий, наиболее свойственных исследуемому аватару. В рамках процедуры подобного анализа формируется облако токенов на основе данных социальных сообществ, приведенные токены квантифицируются и анализируется с точки зрения их важности.

2. Построение модели «Просмотр Лайк - Репост». Данная модель сущностно подобна воронке продаж, а именно - факт просмотра сообщения подобен просмотру товара в интернет-магазине, факт лайка сообщения подобен добавлению в корзину или в «избранное» (закладки, отложенные товары и т.д.), а факт репоста сообщения подобен покупке товара. Данная модель позволяет определить уровень вовлеченности аудитории в контент и склонность к активному взаимодействию с ним.

3. Анализ тональности контента. Данный анализ позволяет определить эмоциональные свойства контента и, как следствие, сформировать наиболее эффективный тон маркетингового обращения к представителям данного аватаpa.

Для целей анализа используются последние 2000 записей в каждом из 4 приведенных социальных сообществ. По результатам был сформирован датафрейм, состоящий из 8000 записей, содержащих текст сообщения, количество просмотров, лайков и репостов.

В первую очередь рассмотрим содержательный анализ контента. Процедура анализа может быть представлена в виде последовательных этапов (рисунок 1).

Первым шагом необходимо выполнить простую квантификацию токенов. По результатам обработки 8000 записей было выявлено 28015 токенов, со среднем числом упоминаний 23.6 раза. Полученные токены распределены в соответствии с законом Ципфа, что указывает на то, что выбросы внутренне присущи системе и носят не случайный характер. К сожалению, дан- 


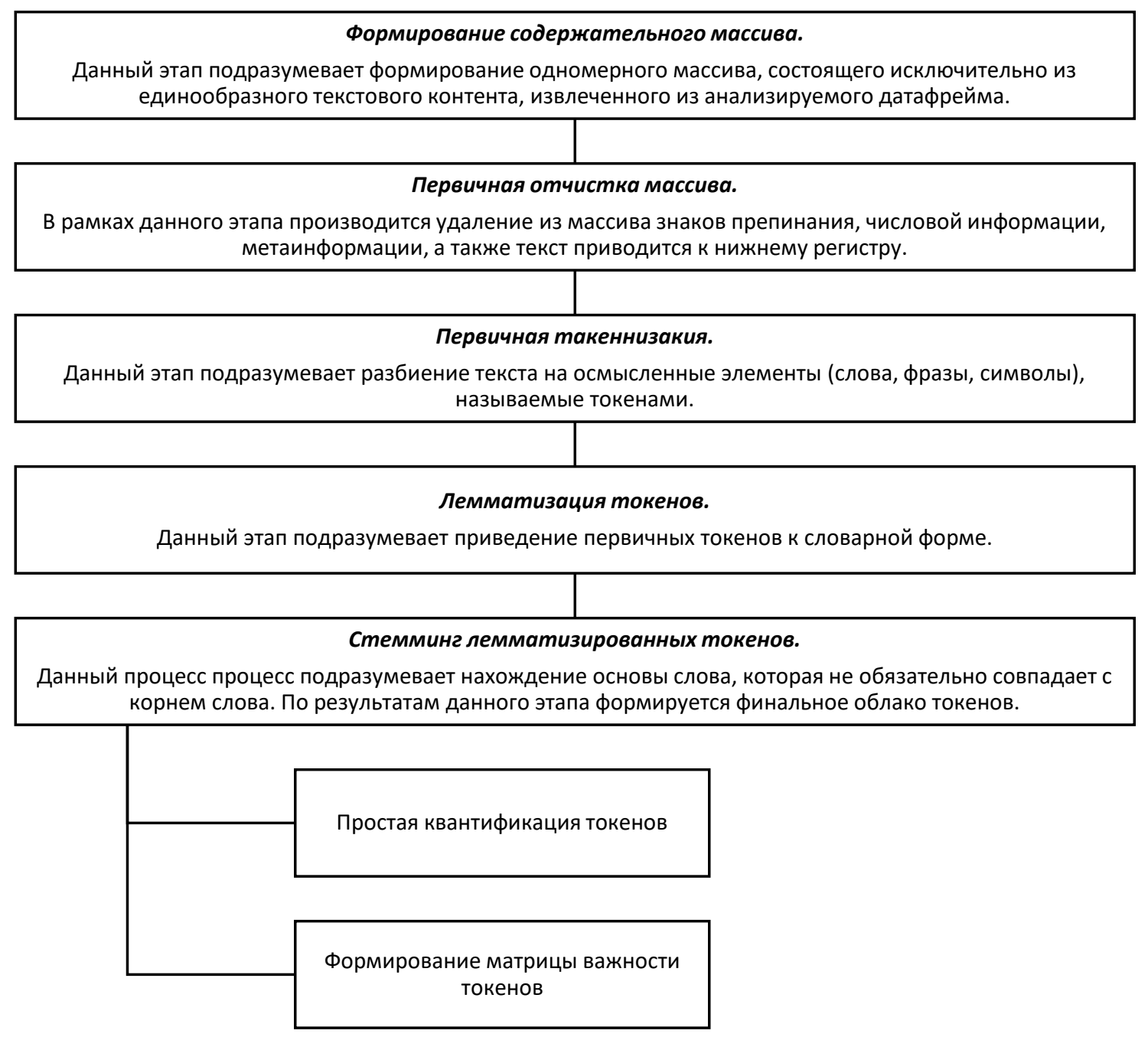

Рисунок 1. Методика содержательного анализа контента

ный массив токенов содержит лексемы с низким уровнем ценности содержания, такие как союзы, предлоги, местоимения и обще употребляемая описательная лексика. В связи с этим, данный массив был исследован экспертно, по результатам чего были выявлены 24 наиболее часто употребляемых содержательных токена (рисунок 2).

По представленным на рисунке 2 данным видно, что содержание контента, свойственного исследуемому аватару, основывается на конкурентно-рыночных категориях. Представителям исследуемого аватара наиболее свойственно оперировать категориями эффективности и развития, первично исследуемым ресурсом для них является трудовой ресурс, область бизнес интересов в первую очередь сосредоточена вокруг продаж, а центральной маркетинговой категорией для них выступает бренд. Таким образом, маркетинговое сообщение, адресованное представителям данного аватара, должно содержать указанные категории. Исследование матрицы важности токенов в данном случае нецелесообразно, так как данный инструмент в первую очередь используется для описания содержания новостного фона.

Далее рассмотрим модель «Просмотр Лайк - Репост». Основой для построения данной модели является расчет показателей описательной статистики по постам в исследуемых сообществах.

В соответствии с приведенными в таблице 1 данными видно, что стандартное отклонение по каждому из исследуемых параметров превышает среднее значение, что указывает на значительный разброс значений. Конверсия просмотров в лайки составляет $0.41 \%$, что является крайне незначительным результатом. Вследствие данного факта можно сделать вывод, 


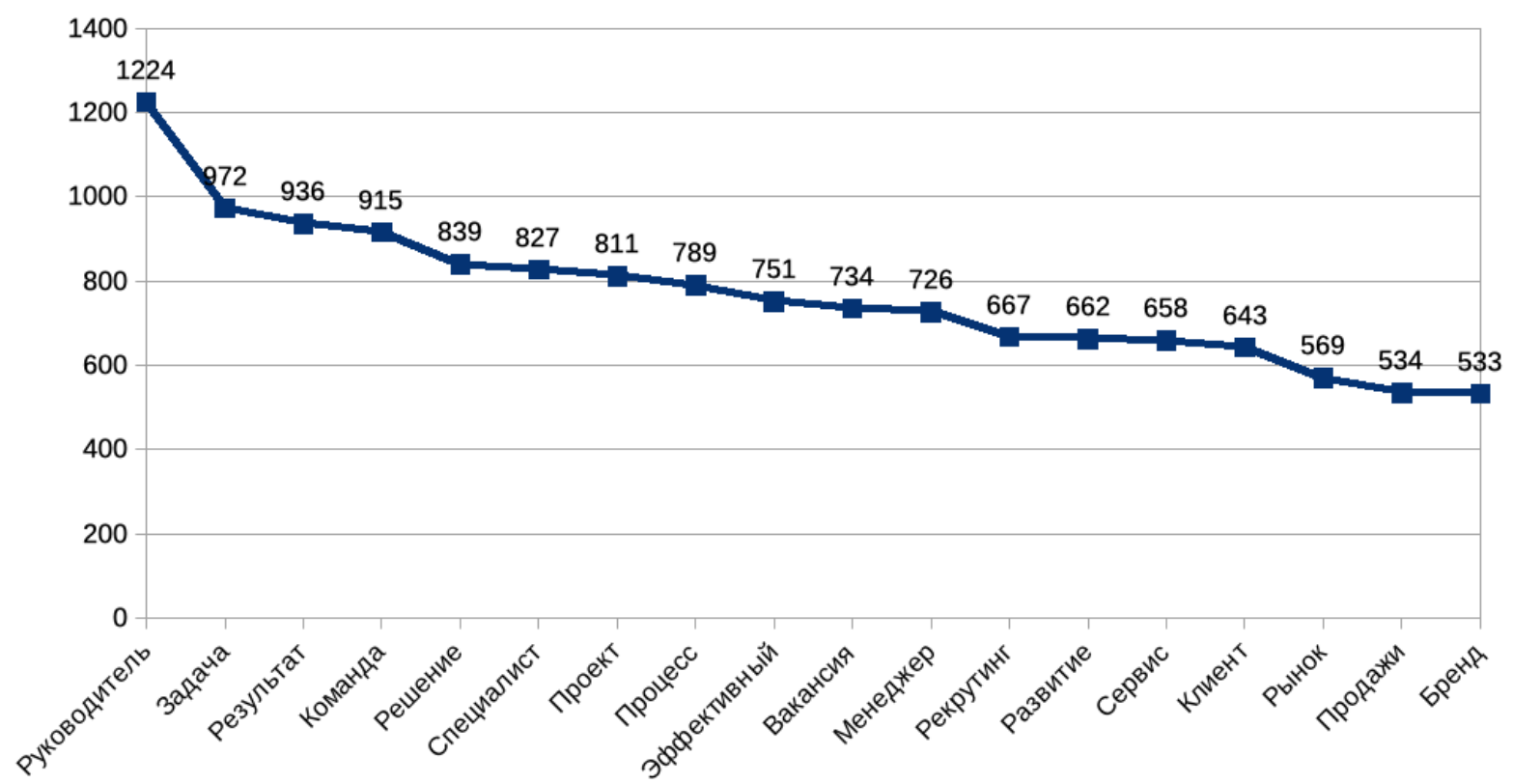

Рисунок 2. Частота упоминания содержательных токенов

Таблица 1. Описательная статистика

\begin{tabular}{|l|c|c|c|}
\hline & Статистика просмотров & Статистика лайков & Статистика репостов \\
\hline Число наблюдений & 8000 & 8000 & 8000 \\
\hline Среднее значение & 16800.09 & 69.58 & 7.56 \\
\hline Стандартное отклонение & 95116.17 & 122.56 & 11.71 \\
\hline Минимум & 1446 & 0 & 0 \\
\hline $\mathbf{2 5 \% ~ к в а р т и л ь ~}$ & 4720.75 & 16 & 2 \\
\hline $\mathbf{5 0 \% ~ к в а р т и л ь ~}$ & 13079 & 31 & 9 \\
\hline $\mathbf{7 5 \% ~ к в а р т и л ь ~}$ & 16773.75 & 65 & 272 \\
\hline Максимум & 4685955 & 3044 & 9 \\
\hline
\end{tabular}

что конверсия потенциальных маркетинговых обращений может быть крайне невысока, следовательно, для приращения конечного результата необходимо наращивать количество маркетинговых обращений (что соответствует стратегии «пропорционального расширения» воронки продаж). Конверсия лайков в репосты составляет $10,87 \%$, что также достаточно невысокий показатель. Данный факт свидетельствует о крайней избирательности представителей исследуемого аватара. При этом, данные выводы справедливы исключительно при достаточно высоком уровне корреляции между исследуемыми показателями. В таблице 2 приведена матрица корреляции.

Как можно видеть из данных таблицы 2, достаточно высокая корреляция наблюдается между лайками и репостами, что указывает на то, что вывод относительно их конверсии является справедливым. В то же время корреляция просмотров и с лайками, и с репостами крайне мала. Следовательно, сам факт просмотра маркетингового обращения практически не влияет на вероятность привлечения. Данное утверждение подтверждается динамикой исследуемых показателей, приведенной на рисунках 3, 4 и 5.

Исходя из представленных на рисунках 3-5 данных, значительный скачок просмотров в 2020 году практически не повлиял на динамику остальных показателей. В тоже время, динамика лайков и репостов крайне похожа. Таким образом, можно говорить о низкой вовлеченности исследуемого аватара с процесс взаимодействия с контентом. Представители аватара готовы потреблять информацию, однако активно взаимодействовать с ней они не готовы. Следовательно, точечное и направленное воздействие на кон- 
Таблица 2. Матрица корреляции в рамках модели «Просмотр - Лайк - Репост»

\begin{tabular}{|l|c|c|c|}
\hline & Статистика лайков & Статистика репостов & Статистика просмотров \\
\hline Статистика лайков & $100 \%$ & $75 \%$ & $17 \%$ \\
\hline Статистика репостов & $75 \%$ & $100 \%$ & $10 \%$ \\
\hline Статистика просмотров & $17 \%$ & $10 \%$ & $100 \%$ \\
\hline
\end{tabular}

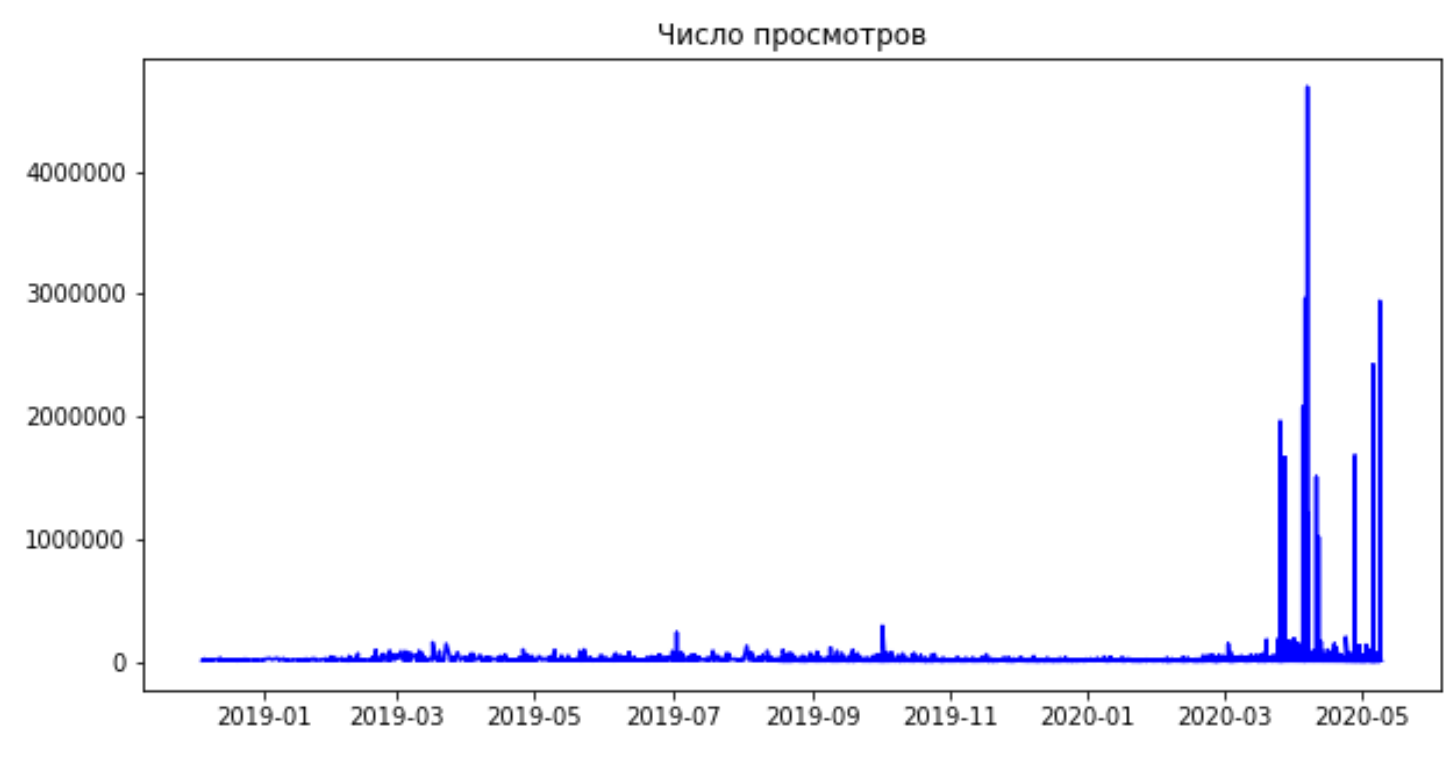

Рисунок 3. Динамика просмотров

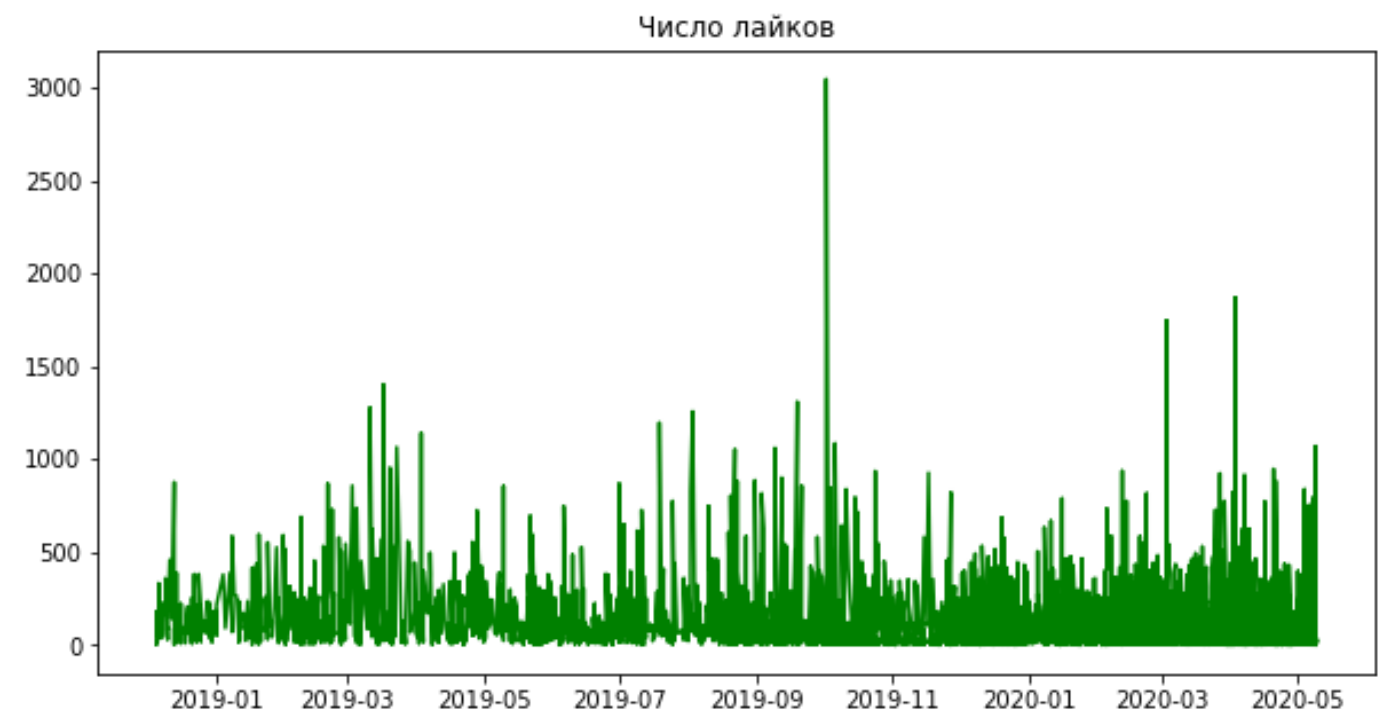

Рисунок 4. Динамика лайков 


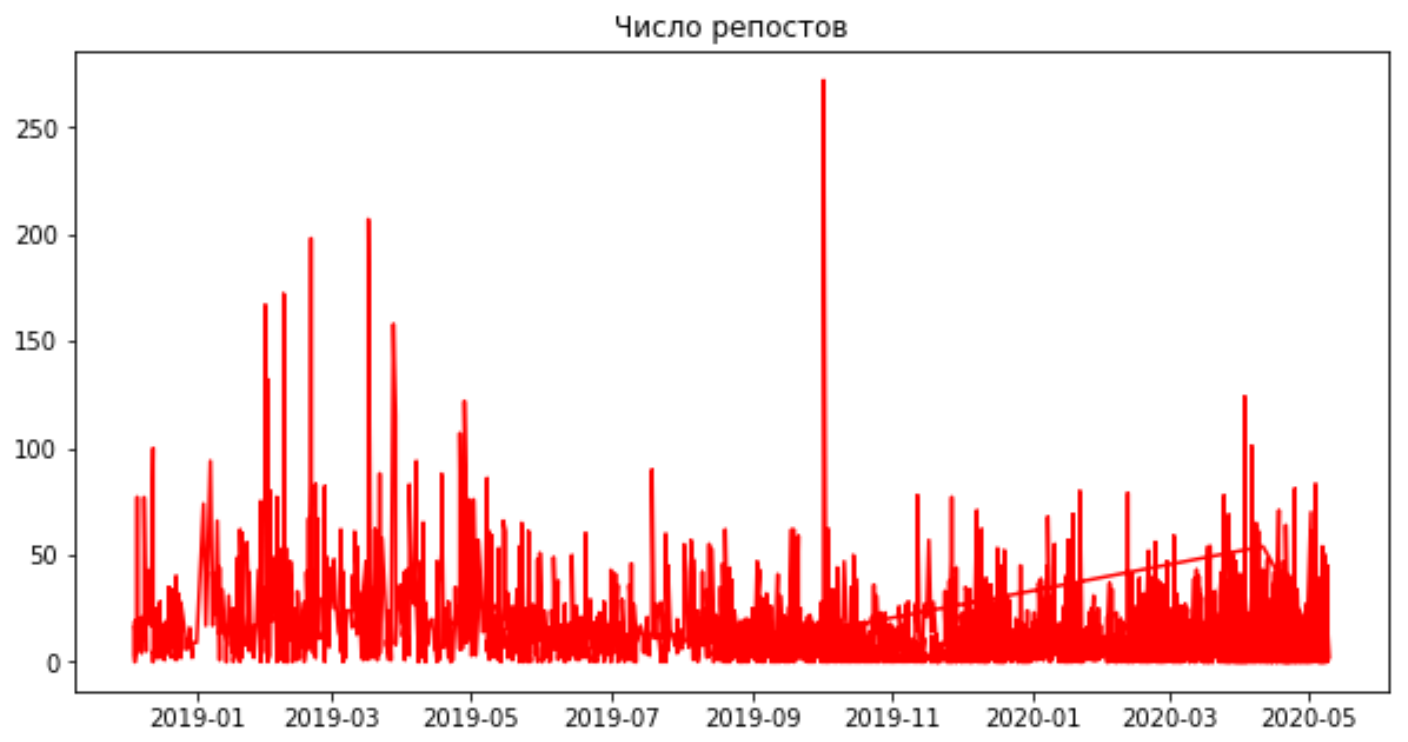

Рисунок 5. Динамика репостов

кретных представителей данного аватара будет значительно более эффективно, чем массовое воздействие. Маркетинговые обращения должны носить индивидуальный характер и кастомизироваться под область интересов конкретного представителя аватара.

В завершении необходимо рассмотреть тональность контента. Для целей анализа тональности используется открытая библиотека Dostoevsky, которая позволяет выявить такие свойства текста, как нейтральность, проходной характер, негативность, позитивность и естественность языка. Каждая из приведенных характеристик измеряется от 0 до 1 . Анализ тональности контента приведен в таблице 3 и на рисунке 6.

Анализируя представленные в таблице 3 и на рисунке 6 данные, можно сделать вывод о том, что потребляемому представителями аватара контенту свойственна общая нейтральность. При этом наиболее репостуемый и лайкуемый контент менее нейтрален, что указывает на необходимость придания маркетинговым обращениям относительно эмоционального окраса.
Приходной характер и естественность языка находится на стабильно низком уровне для всех типов записей, что указывает на необходимость сохранения официальной формы обращения при концентрации на эмоционально-резонансном содержании. Динамика негативности и позитивности контента при этом значительно более сложная. Самому просматриваемому контенту свойственно значительное превышение негативности над позитивностью, в то время как для самого лайкуемого и репостуемого контента данные показатели практически равны друг другу. Следовательно, эмоциональный окрас маркетингового обращения должен быть взвешенным, без превалирования негативного и позитивного контекста.

Проведенный анализ позволил охарактеризовать лексический и тональный характер сообщений, которые будут наиболее благосклонно восприняты представителями аватара банковского сектора ВИП-сегмента, что поможет банку сформировать эффективную контент-стратегию взаимодействия с представителями данного аватара.

Таблица 3. Анализ тональности постов в исследуемых сообществах

\begin{tabular}{|l|c|c|c|c|}
\hline & Все записи & $\begin{array}{c}\text { 25\% самых } \\
\text { просматриваемых }\end{array}$ & $\begin{array}{c}\text { 25\% самых } \\
\text { лайкуемых }\end{array}$ & $\begin{array}{c}\text { 25\% самых } \\
\text { репостуемых }\end{array}$ \\
\hline Нейтральность & 0,902 & 0,761 & 0,766 & 0,766 \\
\hline Проходной характер & 0,049 & 0,052 & 0,043 & 0,043 \\
\hline Негативность & 0,104 & 0,217 & 0,137 & 0,137 \\
\hline Позитивность & 0,033 & 0,021 & 0,119 & 0,119 \\
\hline Естественность языка & 0,015 & 0,015 & 0,010 & 0,010 \\
\hline
\end{tabular}




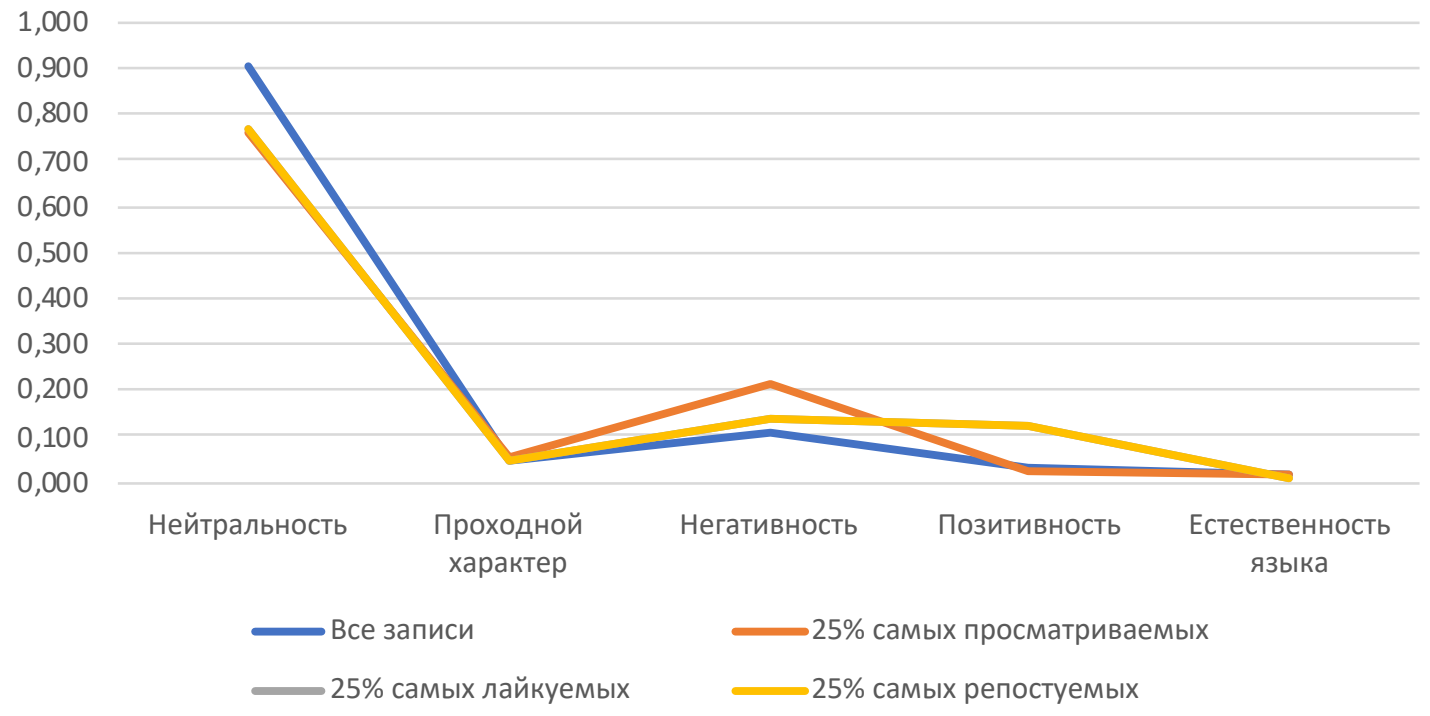

Рисунок 6. Динамика характеристик тональности

\section{Библиографический список}

1. Sandra C.Matz, Joe J. Gladstone, David Stillwell. Money Buys Happiness When Spending Fits Our Personality // Psychological Science. 2016. Volume: 27 issue: 5, page(s): 715-725

2. Ершова А.В. Тенденции эволюции банковского маркетинга в сегменте «ВИП» / Ершова А.В. // Сборник научных трудов VII Международной научно-практической конференции «Маркетинг России».- Москва: «РЭУ имени Г. В.Плеханова», 2019.

3. Конникова О.А., КонниковЕ.А. Синтаксический анализ поведения потребителей в цифровой среде. В сб. Маркетинг сотворчества и глобальные коммуникации доверия. СПб.: Изд-во СПбГЭУ, 2020. С. 132-145

4. Маркетинг и цифровые коммуникации: учебник под ред. О.У.Юлдашевой.- СПб.: Изд-во СПбГЭУ, 2019. $232 \mathrm{c.}$

5. Марков Л. С. Теоретико-методологические основы кластерного подхода.- Новосибирск: ИЭОПП СО РАН, 2015.- 300 c.

6. Ровенский Ю. А. Банковский маркетинг / Ю. А. Ровенский, Н. Н. Наточеева - Изд-во Проспект, 2017. - 201 с. 